\title{
Comunicando diferenças: os processos de hibridização a partir da leitura de la différance nos Estudos Culturais
}

\section{Regiane Regina Ribeiro e Anderson Lopes da Silva}

\section{Resumo}

0 artigo discute o processo de hibridização e as múltiplas leituras do que é ser ou tornar-se híbrido. A abordagem inicia-se por Jacques Derrida, com a discussão a respeito da natureza dividida do signo, la différance, e continua pelos entendimentos consensuais (e alguns dissensos) para teóricos como Stuart Hall, Homi Bhabha, MartínBarbero e García Canclini, localizando, sempre que possível, as reflexões no contexto da América Latina. Conclui-se que a hibridização é potencialmente criativa e ao mesmo tempo conturbada, não se limita às fronteiras geográficas, linguísticas ou de outra ordem, e é fluida, desestabilizadora, ambígua e quase sempre contraditória.

\section{Palavras-Chave}

Hibridização. Estudos Culturais. Comunicação das diferenças. La différance.

Regiane Regina Ribeiro | regianeribeiro5@gmail.com Doutora e Mestra em Comunicação e Semiótica pela Pontifícia Universidade Católica de São Paulo - PUC-SP. Docente permanente do Programa de Pós-Graduação em Comunicação da Universidade Federal do Paraná - PPGCOM/UFPR.

Anderson Lopes da Silva I anderlopps@gmail.com Mestre em Comunicação pelo Programa de Pós-Graduação em Comunicação da Universidade Federal do Paraná - PPGCOM/UFPR. Jornalista, Especialista em Comunicação, Cultura e Arte - PUC-PR e Membro do NEFICS (Núcleo de Estudos em Ficção Seriada) - UFPR/CNPq.

\section{Considerações iniciais}

Pensar a hibridização é pensar a mistura e a mestiçagem como características intrínsecas aos processos de comunicação. Em um ambiente deslocalizado, no qual a ausência de bases fixas e geográficas gera fortes características de glocalização, fragmentação, individualidade, liquidez de relações, os processos de hibridização também produzem, de forma constante, a dúvida e 0 questionamento acerca da construção híbrida das identidades e dos sujeitos pós-modernos. A comunicação e a cultura, entendidas de modo ousadamente amplo, encontram-se também nessa trama de relações híbridas.

Entretanto, mais do que lidar com fusões, acomodações, crioulizações, sincretismos, traduções e adaptações híbridas, pensar a hibridização é também pensar em seus resultados, suas consequências e seus impactos. Em outras palavras, da mesma maneira que os elementos primários que cocriam a hibridização são distintos entre si (como exigência per si para que ela ocorra), os elementos derivados de tal mistura já 
não se caracterizam mais apenas por elencarem esta ou aquela característica advinda de seus elementos originários. 0 terceiro elemento criado pela mistura de dois outros possui aspectos que 0 tornam singular, híbrido e diferente e não apenas uma "antonomásia" por excelência.

Com o objetivo de aprofundar tal discussão, este artigo traz autores e ideias que desenvolvem a compreensão de hibridização cultural com base em confrontos, alguns entendimentos mútuos e experiências que traduzem bem o quão múltiplas são as leituras feitas com relação ao que é ser ou tornar-se híbrido. Como afirma García Canclini:

A construção linguística (Bakhtin, Bhabha) e social (Friedman, Hall, Papastergiadis) do conceito de hibridização colaborou para que a discussão saísse dos discursos biologicistas e essencialistas da identidade, da autenticidade e da pureza cultural. Assim como a mestiçagem contrabalanceou as obsessões por manter incontaminado 0 sangue ou as raças no século XIX e em várias etapas do século XX, a hibridização aparece hoje como 0 conceito que permite leituras abertas $\mathrm{e}$ plurais das misturas históricas, além de construir projetos de convivência despojados das tendências a "resolver" conflitos multidimensionais através de políticas de purificação étnica. [A hibridização] Contribui para identificar e explicar as múttiplas alianças fecundas: por exemplo, do imaginário pré-colombiano com 0 novo-hispânico dos colonizadores e logo com o imaginário das indústrias culturais (Bernand, Gruzinski), da estética popular com a dos turistas (De Grandis), das culturas étnicas nacionais com as das metrópoles (Bhabha), e com as instituições globais (Harvey). Os poucos fragmentos escritos de uma história das hibridizações colocaram em evidên- cia a produtividade e o poder inovador de muitas mestiçagens interculturais (GARCÍA CANCLINI, 2003, p. 4, tradução nossa).

Assim, a abordagem inicia-se por Jacques Derrida com a discussão a respeito da natureza dividida do signo, la différance. Cabe aqui uma ressalva de que, mesmo J. Derrida não fazendo parte dos pensadores fundantes dos Estudos Culturais, grande parte deles o leu, e suas ideias - com destaque para a compreensão de la différance estão explicitamente citadas nas obras de Hall e Bhabha, por exemplo. Por isso, a proposta aqui ensejada também passa pelos entendimentos da hibridização para Stuart Hall, Homi Bhabha, Martín-Barbero e García Canclini.

\section{0 s Estudos Culturais como rede de estudos transdisciplinares}

Definir os Estudos Culturais como uma disciplina e com objetos extremamente delimitados de pesquisa seria negar a essência de sua origem e de seu desenvolvimento. Entendê-lo como uma interdisciplina e até mesmo como uma antidisciplina também não se aproxima de sua compreensão plena. Essas dificuldades de classificação dos Estudos Culturais são motivadas, em sua maioria, pelo amplo espectro de interesses e de temas de seus pesquisadores.

Quem afirma isso é García Canclini, que, ao falar do assunto, utiliza-se da metáfora da urbanização e das criações de ruas para 
exemplificar tais motivações do surgimento dos Estudos Culturais:

Estruturar campos disciplinares foi, do século $\mathrm{XVIII}$ ao XX, como traçar ruas e organizar territórios autônomos num tempo em que havia a necessidade de se defender a especificidade de cada saber frente às totalizações teológicas e filosóficas. Mas as disciplinas se entusiasmaram com esta tarefa urbana e, por razões de segurança, começaram a fechar ruas e a impedir que elas servissem para aquilo que originalmente haviam sido construídas: promover a fácil circulação e o transitar de um bairro ao outro. Os estudos culturais são tentativas de reabertura de avenidas ou passagens para impedir que estas se tornem ampliações privadas de umas poucas casas (GARCÍA CANCLINI, 2004, p. 122, tradução nossa).

Vistos mais como um movimento ou uma rede de estudos (JOHNSON, 2004) do que um campo delimitado e com bases epistemológicas e metodológicas muito restritas, os Estudos Culturais podem ser entendidos como o campo no qual a Comunicação Social, a Sociologia, a Antropologia, a História, a Linguística e os Estudos Literários ganham um olhar que não se contenta com um ou com outro objeto de suas áreas específicas. Pelo contrário, na origem dos Estudos Culturais as leituras do mundo, de seus objetos e de seus sujeitos foram feitas pela lente de pesquisadores que provinham de distintas áreas. Áreas que, ao negarem uma ortodoxia científica rígida demais às pesquisas, se complementavam. Assim, o uso do termo "transdisciplina" se apresenta adequado, uma vez que a visão dessa rede de estudos não se restringe a um campo ou outro, como sustenta García Canclini (2004, p. 84, 119-121).

Cronologicamente, a origem dos Estudos Culturais manifesta-se na década de 1950, na Inglaterra, e, de maneira organizada, apenas em 1964 passa a "existir no escopo da Academia" com a criação do CCCS (Centre for Contemporary Cultural Studies), no departamento de Inglês da Universidade de Birmingham. Como apregoa Ana Carolina Escosteguy, é pela influência de três textos fundamentais que o movimento ganha corpo. Isto é, com The Uses of Literacy (1957), de Richard Hoggart, Culture and Society (1958), de Raymond Williams, e The Making of the English Working-class (1963), de E. P. Thompson, os Estudos Culturais passam a jogar novas luzes sobre as conceituações de cultura e suas interrelações com o poder, a economia e a história "dos de baixo" (ESCOSTEGUY, 2010, p. 27-28).

Já no contexto da América Latina, a mera tradução de "Cultural Studies" para Estudos Culturais não representa uma transposição das ideias do grupo britânico para o grupo dos latinos. Com especificidades que caracterizam 0 movimento no continente, os Estudos Culturais começam a florescer na América Latina durante a década de 1980, valorizando o receptor e sua capacidade tanto de resistir como de responder (visualizando-o como cocriador de mensagens e de sentidos). Entretanto, mais do que seguir a visão de um receptor como sujeito da 
comunicação e da cultura - tal qual já o faziam os britânicos -, os latino-americanos refletem suas ideias em um cenário no qual os conceitos de nacionalismo, populismo, resistência, anarquismo, apropriação e ressemantização eram vivenciados tanto na vida do analista quanto no decorrer de suas análises.

E tudo isso em um momento em que a matriz de pensamento das Ciências Sociais estava cristalizada sob a égide de um marxismo a-historicizado e de uma visão cristã como condições sine qua non para se pensar a comunicação e a cultura nas pesquisas (KUNSCH, 2002, p. 14). Com uma proposta diametralmente oposta, os Estudos Culturais na América Latina começam a questionar os liames e as zonas transfronteiriças da cultura popular e das indústrias culturais, tentando localizar outros aspectos que não apenas os buscados pelos trabalhos de linha marxista-cristã2.

\section{A questão multicultural: desafios e perspectivas}

Pensar a questão multicultural na América Latina requer um olhar sobre como as relações interétnicas fortes e constantes construíram seus espaços. A escravização e a eliminação física do "outro" estiveram sempre presentes no plano das representações e no imaginário social e representaram uma forma violenta de negação da alteridade. Disso emergiram sujeitos que foram massacrados, que souberam resistir e que continuam afirmando suas identidades na sociedade - mesmo obedecendo a relações assimétricas, de subordinação e de acentuada exclusão.

Com relação a essa condição de subordinação e exclusão, García Canclini defende que 0 afastamento dos eixos tradicionais da identidade em um cenário de crescimento e produção global da cultura não pode ser considerado como situação desagradável ou temível, porque vivemos:

um tempo de fraturas e heterogeneidade, de segmentação dentro de cada nação e de comunicações fluidas com as ordens transnacionais da informação, da moda e do saber. Em meio a esta heterogeneidade encontramos códigos que nos unificam, ou que ao menos permitem que nos entendamos (GARCÍA CANCLINI, 1999, p. 85).

Segundo Pinheiro (1995, p. 16), os signos na América Latina apresentam uma mobilidade muito grande, o que não significa que seja diferente em outros lugares do mundo, mas aqui essa mobilidade chega a ser desmesurada. Isso se deve à mestiçagem e ao choque dos processos civilizatórios que fazem os signos 
apresentarem tal característica. Dessa forma, parece ficar mais clara a ideia de Pinheiro quando afirma que se pensa de modo diferente nesse continente e que não seria possível comportarse de outra maneira enquanto descendentes de uma atitude epistemológica diferente, pois a mente trabalha os signos, mais através da fricção de superabundâncias alógenas do que pelos mecanismos binários de inclusão e de exclusão.

Isso significa que os processos de produção de sentido nesse continente apresentam uma diversidade tão exacerbada que tendem a romper a lógica binária e subverter uma valoração simplificadora que exclui o raciocínio e produz uma reação de conforto rápido e cômodo em um mundo de complexidade crescente. Baggio apresenta essa dicotomia como algo:

[...] do pensamento tradicional, com forte influência do pensamento grego que foi mantido no decorrer da história e que ainda se faz presente na sociedade contemporânea, é a criação de linguagem dicotômica pela qual 0 humano é percebido, tratado, educado. Esse paradigma antropológico opõe natureza à cultura, fragmenta o humano em razão-emoção, sujeito-objeto, academicismo-objetividade, corpo-alma, matéria-espírito, masculino-feminino, hemisférios cerebrais direito-esquerdo e o conhecimento a partir de identidade e da não identidade. (1999, p. 26)

Essa atitude epistemológica sui generis se intensifica na segunda metade do século XX, quando se testemunha um grande deslocamento populacional incentivado pelas dinâmicas estabelecidas com os novos reagrupamentos e configurações de forças. Novas saídas do campo e diásporas se desenharam, forçando limites e reconfigurando espaços. Esse processo acarretou mudanças no interior do repertório cultural dos povos, e, consequentemente, na ideia tão fortemente demarcada de "fronteiras culturais" (como é possível também visualizar na América Latina).

Ou seja, os processos migratórios e a desterritorialização desconstituem 0 conceito de comunidade nacional e dificultam a localização linear de repertório de costumes, mitos e práticas que formavam um universo simbólico e, em consequência, configuravam as identidades. Tais repertórios tornaram-se transculturais, implodindo o conceito de fronteiras delimitadas, que não têm correspondência exclusiva com os territórios em que se encontram e tampouco apresentam com estes uma relação de oposição. Nesse contexto, García Canclini (2003) diz que a ideia de hibridização cultural está colocada já na transposição das fronteiras e será percebida pelo processo transcultural, que caracteriza a expressão das culturas. Isso determinará uma construção identitária sempre em trânsito, na qual a cultura desterritorializada buscará seu "não lugar", ocupando de maneira incisiva um novo locus de expressão.

Assim, na América Latina, a fronteira se configura como lugar onde uma cultura se expressa trazendo em si a marca de uma relação desigual, na qual a violência é exercida no confronto com o outro, com a alteridade. E, quando não existe maneira 
de retornar ao lugar de origem, os espaços de exploração e a articulação das identidades híbridas devem construir-se com base nas discussões sobre diversidade, as quais são produzidas dentro dos espaços de significação e das estruturas de poder, problematizando-as e provocando o questionamento em torno da experimentação de identidades alternativas.

\section{Jacques Derrida: o filósofo de la différance}

A definição do sentido de la différance torna-se complicada já no momento de uma possível tradução do termo à língua portuguesa. Isso porque, em francês, o vocábulo produz uma dupla significação por tratar-se de um neografismo homófono à palavra différence (diferença, em português). A troca de um $a$ por um $e$, como se poderia esperar, não é uma simples mudança sem consequências maiores. Quando Jacques Derrida (1930-2004) proferiu sua palestra "La Différance", na Sociedade Francesa de Filosofia, em 27 de janeiro de 1968, tal "falha silenciosa à ortografia" foi muito significativa, ou seja, a troca do "legítimo" $e$ pelo "transgressor" a, como colocam os tradutores de "Margens da Filosofia" (1991), trouxe uma crítica à tradição filosófica ocidental, de modo sutil, que deixava explícito um exemplo de seus sintomas: o fonocentrismo, ou seja, 0 privilégio da fala sobre a escrita.

0 filósofo Lázaro Barbosa destaca que la différance mostra, dessa maneira "[...] que não só a escrita não dá conta de representar a fala de forma isonômica e vice-versa", como também radicaliza "ainda mais os pressupostos e as consequências do conceito de representação, tão caro à filosofia da identidade que predomina no Ocidente há séculos, desde Platão e Aristóteles até Saussure e Lévi-Strauss" (BARBOSA, 2012, p. 119).

Salientando que la différance não é nem uma palavra e nem um conceito, o filósofo retoma os dois sentidos do verbo diferir (verbo latino differre): 0 de diferir na temporização ("temporizar é recorrer, consciente ou inconscientemente, à mediação temporal e temporizada de um desvio que suspende a consumação e a satisfação do desejo ou da vontade, realizando-o de fato de um modo que lhe anula ou modera 0 efeito") e de diferir com 0 sentido de não ser idêntico (dos aspectos relacionados à "alteridade de dissemelhança") (DERRIDA, 1991, p. 38-39).

Pós-estruturalista, o francês Jacques Derrida, filósofo da desconstrução, apresenta la différance como algo que remete ou reenvia para dois movimentos distintos, a saber: 1) a diferenciação como a produção de diferenças, alteridades, das não identidades em um sistema sígnico - pondo em xeque pressupostos da linguística de Saussure; e 2) o espaçamento, o desvio, a temporização, o retardamento, o cálculo sucinto "que faz com que um sentido seja sempre antecipado ou restabelecido em posteridade" (BENNINGTON; DERRIDA, 1996, p. 58). Essa "origem" estruturada 
e "diferante" de diferenças, como coloca Derrida (1991, p. 43), é uma não origem, uma vez que, por não ser um fundamento ou um ponto de partida simplista, de igual forma não possui um fim ou ponto de chegada: é uma "estratégia sem finalidade" (DERRIDA, 1991, p. 38).

Sobre 0 assunto, Derrida afirma que la différance é o que faz com que o movimento da significação só se torne possível por cada elemento dito "presente", ou seja, aquele que aparece sobre a cena da presença possa se relacionar com outra coisa que não ele próprio (DERRIDA, 1991, p. 45). Dessa forma, prossegue ele, cada elemento do presente, guardando em si a marca do elemento passado, também se deixa "moldar", refazer-se por sua relação com o elemento futuro. Assim:

\begin{abstract}
É necessário que um intervalo o separe do que não é ele para que ele seja ele mesmo, mas esse intervalo que 0 constitui em presente deve, no mesmo lance, dividir o presente em si mesmo, cindindo, assim, como o presente, tudo 0 que a partir dele se pode pensar, ou seja, todo 0 ente na nossa língua metafísica, particularmente a substância e 0 sujeito: Esse intervalo constituindo-se, dividindo-se dinamicamente, é aquilo a que podemos chamar espaçamento, devir-espaço do tempo ou devir-tempo do espaço (temporização) (DERRIDA, 1991, p. 45).
\end{abstract}

Dessa forma, la différance seria "0 movimento do jogo que produz as diferenças, os efeitos de diferença”, uma estratégia. Em outras palavras: la différance "não é mais simplesmente um conceito, mas a possibilidade de conceitualidade, do processo e do sistema conceitual em geral" (SANTIAGO, 1976, p. 23-24).
Tal jogo de estratégia tem por norte a dualidade ausência/presença. E, desse modo, consegue apresentar a natureza dividida do signo, isto é, la différance possui o duplo significado de se sobrepor e, ao mesmo tempo, ser distinto. John Storey, em "Teoría Cultural y Popular", comenta que Derrida, mesmo levando em consideração o sistema de diferenças como a localização que faz com que os signos produzam sentido (noção proposta por Saussure), acrescenta a ele a ideia de que um "significado sempre é adiado, nunca está completamente presente, sempre presente e ausente". E dá como exemplo o dicionário: "se buscamos o significado de uma palavra em um dicionário, encontramos um contínuo adiamento do significado", explica Storey (2001, p. 123, tradução nossa). Um jogo infinito de reenvios de sentido e de signos que se remetem na presença/ausência.

\section{A leitura de la différance por um viés culturalista}

\begin{abstract}
Mas, afinal, qual a leitura que os Estudos
Culturais fazem da obra de Derrida? Qual ressignificação é dada pelos teóricos da cultura acerca de la différance? Continuando no tom ensaístico que constitui este trabalho, é possível responder afirmando que Hall e Bhabha são os dois autores que mais frequentemente fazem uso da desconstrução e do vocabulário derrideano.
\end{abstract}

0 exemplo das utilizações da obra de Derrida em Hall é bem mais nítido do que nos outros 
autores. Para se ter uma ideia, Hall recusa-se a pensar a identidade cultural dos povos do Caribe em concepções binárias ou até mesmo excludentes: 0 autor passa a visualizar $l a$ différance como a saída para suas explicações. A compreensão da pós-colonialização em Hall baseia-se em uma "releitura" de Derrida, uma vez que ela é entendida como um processo global fundamentalmente transnacional e transcultural. Lázaro Barbosa comenta que tal "ruptura indica uma nova leitura das identidades culturais que se pretendem autônomas e autoproduzidas, pelo jogo da différance, no qual colonizadores e colonizados se inscrevem um através do discurso do outro" e, como consequência dessa ambivalência, eles se apropriam "mutuamente em suas semelhanças e diferenças" (BARBOSA, 2012, p. 120).

As diferenças que constituem a identidade cultural caribenha ocorrem por meio de "places de passage, e significados que são posicionais e relacionais, sempre em deslize ao longo de um espectro sem começo nem fim", explica Hall (2003, p. 33). E, de maneira mais explícita: "Naturalmente, o que faço aqui é traduzir da filosofia à cultura e expandir o conceito de Derrida sem autorização - embora, espero, não 0 faça contra o espírito de seu sentido/propósito" (HALL, 2003, p. 92). Já Bhabha, ao criticar algumas metodologias de análise do discurso do colonizador sobre o colonizado, recorre a Jacques Derrida pela ideia de não separar aquele que pesquisa daquilo/daquele que é pesquisado. Seu entendimento, com base na obra derrideana, é levado a praticar a desconstrução como modo crítico de abordar o "real" e 0 "autêntico", isto é, a crítica ao que se toma por realidade e sua demasiada busca por um discurso científico limpo de qualquer traço subjetivo. Outro uso de Derrida por parte de Bhabha é descrito por Souza pela correlação conceitual. É interessante notar que as duas conotações de diferir descritas pelo filósofo francês também são utilizadas pelo crítico indiano. 0 conceito de imagem em Bhabha, por exemplo, é lido como a 'economia do suplemento' para Derrida, e é tido como "perigoso": porque a imagem em si, como ponto de identidade, é ambivalente, pois é representação e signo, ou seja, é sempre "fendida", tanto espacialmente (torna presente algo que está ausente) quanto temporalmente (representa algo que veio antes e, por isso, torna-se uma repetição) (SOUZA, 2004).

Homi Bhabha não apenas faz uso direto de Derrida, como também o "defende" ao rejeitar a crítica que é apontada ao filósofo e, por conseguinte, ao próprio trabalho também. A crítica diz respeito ao a-historicismo que, supostamente, estaria arraigado nas suas discussões acerca da indeterminação e da ambivalência: tal valorização seria desnecessária e irresponsável em relação aos referentes históricos que rodeiam os seus debates.

Souza diz que, ao sair em defesa de Derrida e enfatizar a hibridização que permeia a linguagem, Homi Bhabha procura mostrar que é impossível lidar com tais questões tentando caracterizar a linguagem e seus usos com "valores objetivos e 
factuais". Entretanto, tanto ele como Derrida, quando lançam mão de la différance em suas obras, de forma alguma estão "a-historicizando" seus debates, tendo em vista que "toda vez que se atribui uma validade intrínseca a algo, transcendendo limites de tempo e espaço, é necessário incansavelmente contextualizar e historicizar tal atribuição". Mais do que isso: é preciso "desuniversalizar" e "mostrar" tais questões como produtos de suas condições históricas, mas também culturais e ideológicas produtivas, finaliza Souza (2004).

\section{Qual é o espaço da diferença na comunicação?}

As mídias como processos culturais e comunicacionais criam seus moldes e seus sistemas considerados aqui como elementos de importância na produção de sentido e (re) construção social midiatizada. Na atualidade, apresenta-se paralelamente à globalização econômica a existência de uma globalização de práticas sociais, em um contexto atravessado por diferentes mídias que se entrelaçam configurando um complexo cenário midiatizado.

Nesse conjunto de acontecimentos, ganham força os movimentos/fluxos de sujeitos pela experiência da miscigenação cultural, da diferença por meio da qual estabelecem uma linha de jogo entre duas forças: uma que empurra e outra que puxa.

Desse modo, o conceito de fronteiras - como muro e defesa - sofre uma alteração, passandose a considerá-las pontos de contato, espaços de relações que se (re)organizam pela intervenção dos sujeitos através delas. 0 redimensionamento desses pontos/superfícies de contato, nas relações, é consequência das mudanças rápidas e progressivas do conceito tradicional de fronteiras, por intermédio das quais os indivíduos projetamse no corporal e no imaginário.

A contribuição dessa reflexão (para além do que os autores aqui utilizados já discutem) está não na problematização do conceito $0^{3}$ do ponto de vista comunicacional e intercultural. É dizer que: somente a partir do tensionamento conceitual entre aquilo que é abordado por García Canclini (2011), por exemplo, e os objetos empíricos estudados pelo campo da comunicaçã $0^{4}$ é que os processos podem ser correlacionados entre teoria e prática, entre plano conceitual e plano praxiológico. Em outras palavras, a conceituação de hibridização cultural encontra-se no plano das ideias e das reflexões defendidas pelas múltiplas visões objeto de seu livro não é a "hibridez, e, sim, os processos de hibridação" (GARCíA CANCLNI, 2011, p. XXVII). Logo, a discussão centra-se neste artigo não na busca de um tensionamento conceitual que focalize a hibridização em si, mas, de modo correlato, uma busca que traga os processos hibridizadores sob o foco da comunicação e sua interface com outros campos (como a cultura).

4 Como as telenovelas, processos de hibridização aliados aos sistemas culturais, a discussão das mediações socioculturais para além dos meios massivos, entre outros objetos. 
discutidos neste artigo, mas os processos e as formas de hibridização comentadas por eles podem ser analisados para além do estudo seminal antropológico, literário, filosófico, folclórico e apenas cultural dos autores, ou seja, eles podem ser lidos na interface da comunicação e dos estudos culturais, destacando, entre outras coisas, a especificidade do teor comunicativo de massa, do consumo cultural e das tensões entre 0 antigo e moderno, entre 0 local e 0 global, etc.

\section{A América Latina pode ser vista como 0} exemplo mais visível desses novos processos de produção industrial, eletrônica e informática que reorganizam o que antes era dividido em fronteiras do culto e do popular. Martín-Barbero (2002, p. 146) observa que as indústrias culturais estão reorganizando não apenas as identidades subjetivas e coletivas, mas também formas de diferenciação simbólica. 0 autor ainda explica que é justamente pelo estudo sistemático dessas produções "mestiças" e dos processos de comunicação massiva que será possível compreender essas novas demarcações: agora reorganizadas em uma sociedade também híbrida e marcada pela diferença.

Isso deu origem ao conceito de "região transfronteiriça", segundo o qual coexistem, em um mesmo grupo, vários códigos simbólicos que garantem uma identidade multiétnica, transitória, mutante e migrante, formada por elementos cruzados de várias culturas. A definição deixa de ser unicamente socioespacial para assumir-se sociocomunicacional, atuando em redes comunicacionais deslocadas e onde a diferença marca presença (GARCÍA CANCLINI, 1993, p. 44).

Os processos migratórios e a tecnologização das relações, inseridas em um espaço no qual convivem simultaneamente todas as temporalidades históricas, acarretam uma desarticulação das séries culturais classificadas como "cultas", "populares", e, ainda, "massivas", ou, como coloca McCarthy, o "olhar do poder, suas normas e pressupostos, precisa ser desconstruído" (1998, p. 156, tradução nossa).

Assim, fronteira tensiona e confronta as realidades. Essas, por sua vez, são fortalecidas nas discussões raciais, étnicas, de gênero, no meio ambiente, nas concepções religiosas, na sexualidade, na política do corpo, na língua, etc. García Canclini concorda com o fato de que deve ser relativizada a noção de identidade. Afirmar os processos de hibridação é esvaziar a ideia de identidade "autêntica", tal como a concebe uma forte tendência da Antropologia, assim como alguns enfoques de pesquisadores implicados com os Estudos Culturais. Dessa maneira, 0 autor propõe um deslocamento do objeto de estudo: da identidade para a heterogeneidade e a hibridização interculturais.

As grandes cidades, palcos dos processos mais interessantes de hibridização, apresentam "fronteiras porosas", permeáveis às redes 
transcomunicacionais, viabilizadoras dos

processos que impulsionam as culturas híbridas, as quais, então, liberariam as análises culturais de seus processos de fundamentalismos identitários (GARCÍA CANCLINI, 2000).

\section{A criatividade e 0 antagonismo na cultura: os processos de hibridização em Hall}

A conceituação de Stuart Hall dada ao hibridismo confunde-se com sua experiência enquanto reflexo de um fluxo migratório de caribenhos para a Inglaterra no século passado. Dito de outro modo, tal reflexo é projetado em suas obras como 0 retrato daquilo que se convencionou chamar de estudos pós-colonialistas e análises pautadas na diferença, na desterritorialização e no descolecionamento de bases tidas como puras e tradicionais. Hall compreende a hibridização cultural como algo que "não se refere a indivíduos híbridos, que podem ser contrastados com os 'tradicionais' e 'modernos' como sujeitos plenamente formados". Para ele, o conceito trata-se "de um processo de tradução cultural, agonístico, uma vez que nunca se completa, mas que permanece em sua indecidibilidade" (HALL, 2003, p. 74).

E é justamente durante a tradução cultural que os sujeitos diaspóricos têm diante de si uma cultura que não as assimila, que não as integra e, ao mesmo tempo, não perdem completamente suas identidades originárias: elas ainda guardam, muitas vezes pela forma oral, características que são de seus antigos países. 0 destaque da conceituação de hibridização para Hall encontra-se no seu entendimento dos processos hibridizadores como formas potenciais de fontes criativas, isto é, formas criadoras de novas percepções de mundo. 0 teórico cultural jamaicano afirma isso dizendo que "o 'hibridismo' e o sincretismo - a fusão entre diferentes tradições culturais - são uma poderosa fonte criativa", que produz inovadoras formas de cultura, "mais apropriadas à modernidade tardia que às velhas e contestadas identidades do passado" (HALL, 2000, p. 91).

Com base na leitura que Hall faz de Jacques Derrida, o pesquisador Lázaro Barbosa comenta que, ao ressaltar toda a dinâmica da hibridização nos processos multiculturais, diaspóricos e póscoloniais, o pesquisador jamaicano pautou sua busca na "superação de dicotomias envolvendo os discursos políticos, culturais e acadêmicos" advindos das tradicionais direita e esquerda. "Em suma, se Hall não pode ser considerado um teórico derrideano, pelo menos é digno de atenção pelos argumentos defendidos e pela disseminação da différance nos estudos culturais" (BARB0SA, 2012, p. 123).

De igual modo, pensar o processo da hibridização, para o pesquisador, é questionar-se sobre aquilo que ele chama de "proliferação subalterna da diferença" (HALL, 2003, p. 60), isto é, a desestabilização da cultura e as perturbações sociais que - também vistas na linguagem - são promovidas pelo embate entre o moderno e 0 
antigo, entre 0 que se entende por culto e não culto, entre classes superiores e inferiores.

De todos esses apontamentos, há pelo menos uma certeza postulada por Stuart Hall: entre esses locais de contato e entre as comunidades e os sujeitos imaginados (termos tomados de Benedict Anderson), a diáspora muda os que saem, muda os que já estão e muda também os que ficaram. Para entendê-los, é preciso compreender os lugares de passagem e de diferença, quer dizer, os locais onde os significados também se tornam relacionais, posicionais e nunca definitivos.

Assim, seguindo o pensamento de que a hibridização é potencialmente criativa e ao mesmo tempo conturbada, as desestabilizações da cultura também são potenciais. Pensar nessas desestabilizações é pôr sob tensão a suposta neutralidade cultural por parte de um estado liberal, por exemplo, com o pensamento de uma "cultura além das culturas" versus os "particularismos" que se universalizaram de modo hegemônico como “isto é cultura, isto não é cultura”. É por isso que Hall aponta a hibridização como 0 desestabilizador cultural por excelência: 0 híbrido não aceita conceitos fechados nem oposições binárias.

\section{A tradução cultural em Bhabha: a hibridização vista pelas representações linguísticas e identitárias}

Tal qual Stuart Hall, o crítico indiano Homi Bhabha escreve, pensa e vive as problemáticas suscitadas pelo pós-colonialismo: nesse caso, tendo a Inglaterra (colonizadora) e a Índia (colonizada) como o pano de fundo de suas discussões. Suas ideias e seus conceitos com relação à hibridização surgem em um contexto de confronto na literatura de ex-colonizados e excolonizadores; um embate entre qual das formas de representação literária representaria mais ou menos fidedignamente a realidade dos nativos.

A preocupação com os processos híbridos surge de sua experiência própria como membro de uma elite local (os Parsi, de Mumbai), presente em uma sociedade colonizada pelos ingleses durante dois séculos. De igual modo, tais discussões iniciam-se também do objeto de análise de seus primeiros trabalhos, isto é, o discurso colonial britânico na Índia do século XIX.

Ao criticar a análise de imagens e a análise ideológica dos textos, Bhabha não traz a mesma abordagem "realista" da literatura e das suas representações identitárias da cultura e da hibridização. Ele se utiliza da desconstrução de Derrida: a crítica de Bhabha está voltada principalmente à representação violenta que separa sujeito e objeto, fixando, sempre, 0 sujeito em uma posição de inteligibilidade hierarquicamente privilegiada (SOUZA, 2004).

Em outras palavras, de acordo com Souza (2004), é pelo caminho da linguagem que Homi Bhabha busca a identidade, ou seja, é no nível do discurso que ele traça sua rota com 0 
intuito de compreender as traduções culturais e a hibridização que as constituem. 0 enfoque de Bhabha recai no que estava em jogo, ou seja, entender "se eram as linguagens usadas para representar os sujeitos ou [...] a questão da construção da identidade" que realmente interessava, explica Souza (2004, p. 114).

A busca pela identidade, conforme Homi Bhabha, é sempre agonística porque a identidade é sempre uma imagem, que continua sendo imagem, ainda que "muito autêntica" (por isso, nunca é substancial). Bhabha explica que 0 acesso à imagem da identidade seguindo uma imagem só é possível por meio de uma negação do sentido de originalidade ou da ideia de plenitude, "através do princípio de deslocamento e diferenciação (ausência/ presença; representação/repetição)" que, de uma maneira ou de outra, torna a realidade ambígua. E, nesses termos, o processo relacional da identidade (a imagem) é, de modo dúbio, uma "substituição metafórica, uma ilusão de presença" e, por isso mesmo, uma "fronteira movediça da alteridade na identidade" (BHABHA, 2010).

Assim, quaisquer das tentativas de representação tornam-se híbridas por conterem traços dos dois discursos, dos discursos (o do colonizado e do colonizador) que se misturam em um complexo jogo de alteridade e distinção, no qual intentar uma autenticidade é algo impossível. Em uma definição que antecipa suas discussões acerca do entendimento de uma "tradução cultural", 0 crítico indiano menciona que a hibridização é um modo de conhecimento, um meio de entender e também de perceber as transformações conflitantes - sociais e culturais (BHABHA, 2002 apud SOUZA, 2004, p. 113).

Dessa maneira, pensar a hibridização em Bhabha é partir do conceito de discurso como uma prática significatória. Em outras palavras, na esfera linguística a identidade e a sua representação estão umbilicalmente presentes em um "processo que postula a significação como uma produção sistêmica situada dentro de determinados sistemas e instituições de representação ideológicos, históricos, estéticos, políticos" da tradução cultural (BHABHA, 1984, p. 98).

Por fim, outro aspecto relevante da conceituação de hibridização em Homi Bhabha é que ele a percebe como um potencial ato político, ético e libertário - em especial, pela força das minorias. Para 0 autor, não importam muito os dois espaços ou momentos originários do híbrido, mas, sim, o terceiro espaço que possibilita 0 surgimento de outras posições e futuros espaços. É esse terceiro espaço híbrido que promove e "desloca as histórias que 0 constituem, e estabelece novas estruturas de autoridade, novas iniciativas políticas" que, "ao serem mal compreendidas através da sabedoria normativa", a desestabilizam e abrem brechas para uma miríade de compreensões da cultura (BHABHA, 1990, p. 211). 


\section{Considerações Finais}

Os Estudos Culturais, com sua flexibilidade e abertura a outros campos do conhecimento, possibilitam leituras dos processos hibridizadores que se complementam e que também se confrontam em alguns casos. Entretanto, as múltiplas leituras da hibridização a partir dos teóricos da cultura possuem algo em comum que traduz bem a essência de suas ideias: a hibridização é ambígua e sempre contraditória.

E é justamente por seu caráter dúbio, em especial pela recusa em pensar apenas nos elementos que possibilitam a hibridização e que se esquecem dos resultados, que la différance em Jacques Derrida é lida e transposta nas concepções dos autores discutidos neste artigo. Em outros termos, pensar na dubiedade da ausência e presença, além de se questionar acerca da existência do diferente na sociedade, faz com que a hibridização seja tensionada e sempre refletida na vida dos sujeitos e nas suas formas de enxergar o mundo.

Assim, a visão de Stuart Hall com relação à hibridização cultural aproxima-se muito da conceituação proposta por Homi Bhabha, especialmente por usar uma terminologia idêntica: a tradução cultural. A seu modo, Hall define tal processo tradutório como o momento de negociação entre novas e antigas matrizes culturais, momentos que são vivenciados por pessoas que, como ele, emigraram de sua terra natal. Todavia, os aspectos relativos à linguagem e aos estereótipos não são considerados na mesma medida que Bhabha. Diferentemente de García Canclini, que vê na hibridização um processo multicultural e capaz de possibilitar o respeito, a valorização e a tolerância às diversidades culturais, para Hall e Bhabha isso resulta do choque, do embate e, por isso, não traz consigo uma via constante de entendimento, ou seja, a visão do autor jamaicano e a do autor indiano não são tão "elogiosas" em relação aos processos de mestiçagem, de mistura.

Em outra comparação conceitual, agora com Homi Bhabha, é possível perceber que também existem preocupações em torno da linguagem e vinculadas à hibridização por parte de García Canclini. A linguagem é apontada pelo argentino como perturbadora da sociedade normativa, como intransigente quando os assuntos são regras e convenções. Ele comenta que as lutas semânticas para neutralizar, perturbar a mensagem dos outros ou mudar seu significado, e subordinar os demais à própria lógica, são elementos de uma pseudorrealidade, de uma encenação de conflitos entre os atores políticos e sociais, isto é, entre a história, o Estado, a publicidade, o mercado e também a luta popular para sobreviver. Percebe-se, ainda, que, para García Canclini, mais importante que configurar o termo na perspectiva da mestiçagem, crioulização, sincretismo, é construir princípios teóricos e procedimentos metodológicos que nos ajudem a entender as diferenças no sentido de perceber 0 que se ganha ou se perde ao hibridar-se. 
Dessa maneira, como pressuposto básico das reflexões que seguem o viés dos Estudos Culturais, seria uma aporia, para fazer uso de termos derrideanos, dar como encerrada a discussão conceitual sobre a hibridização cultural, uma vez que verdades incontestáveis não fazem parte do escopo teórico dessa rede de estudos. Pelo contrário, o que se intentou neste trabalho foi mostrar um panorama, obviamente incompleto, das variadas concepções que os processos hibridizadores possuem na atualidade. Uma hibridização que não se limita às fronteiras geográficas, linguísticas ou de outra ordem, mas que é fluida e desestabilizadora.

\section{Referências}

BARBOSA, L. Hall leitor de Derrida. Revista

Urutágua, Maringá, nº 26, maio 2012, p.114-124. Disponível em: < http://periodicos.uem.br/ojs/index. php/Urutagua/article/viewFile/14656/9192> . Acesso em: 14 de janeiro de 2014.

BENNINGTON, G.; DERRIDA, J. Jacques Derrida. (Trad. Anamaria Skinner). Rio de Janeiro: Jorge Zahar, 1996.

BHABA, H. Representation and the Colonial Text: a critical exploration of some forms of mimeticism. In: GLOVERSMITH, F. (ed.), The theory of reading. Brigthon: Harvester, 1984, p. 93-122.

. The Third Space. In: RUTHERFORD, J. (ed.), Identity: community, culture, difference, London: Lawrence \& Wishart Rutherford, 1990, p 207-215.

o local da cultura. Belo Horizonte:

Autêntica, 2010.

DERRIDA, J. Margens da filosofia. (Trad. Joaquim T. Costa; Antonio M. Magalhães). Campinas: Papirus, 1991.

\section{ESCOSTEGUY, A. C. Cartografia dos Estudos}

Culturais: uma versão latino-americana. Belo

Horizonte: Autêntica, 2001.

GARCÍA CANCLINI, N. Consumidores e Cidadãos.

Conflitos multiculturais da globalização. $4^{\mathrm{a}}$ ed. Rio de Janeiro, Editora UFRJ, 1999.

Culturas híbridas: estratégias para entrar e sair da modernidade. (Trad. Heloísa P. Cintrão e Ana Regina Lessa). $4^{\mathrm{a}}$ ed. São Paulo: Edusp, 2011.

Diferentes, desiguales y desconectados: mapas de la interculturalidad. Gedisa Editorial: Barcelona, 2004.

Malestar en los Estudios Culturales. Revista

Fractal, México, v. 2, nº 6, jul./set. 1997, p. 45-60. Disponível em: < http://www.mxfractal.org/F6cancli. html>. Acesso em: 11 set. 2014.

. Noticias recientes sobre hibridación.

Biblioteca de Documentos Globalizacion. Org. Texto apresentado no VI Congreso de la SibE, julho de 2000.

Disponível em: http://www.globalizacion.org/biblioteca/ CanciliniHibridacionNoticiasRecientes.htm. Acesso em: 22 de outubro de 2014.

HALL, S. A identidade cultural na pós-modernidade. $3^{\mathrm{a}}$ ed. Rio de Janeiro: DP\&A, 2000.

Da diáspora: identidades e mediações culturais. São Paulo: Humanitas, 2003.

JOHNSON, R. 0 que é, afinal, Estudos Culturais? In: SILVA, T. (Trad./Org.). 0 que é, afinal, Estudos Culturais? Belo Horizonte: Autêntica, 2004, p. 9-131.

KUNSCH, W. L. Introdução: as matrizes marxistas e cristãs das idéias comunicacionais na América Latina. In: MELO, J. M.; GOBBI, M. C.; KUNSCH, W. L. (Orgs.). Matrizes comunicacionais Latino-americanas - Marxismo e Cristianismo. São Paulo: Ed. UMESP/ UNESC0, 2002, p. 13-25.

MARTÍN-BARBERO, J. Dos meios às mediações: comunicação, cultura e hegemonia. (Trad. Ronald 
Polito; Sérgio Alcides). $6^{a}$ ed. Rio de Janeiro: Editora UFRJ, 2009.

Oficio de cartógrafo: travesías

latinoamericanas de la comunicación en la cultura.

Santiago, Chile: Fondo de Cultura Económica, 2002.

McCARTHY, C. The uses of culture: education and the limits of ethnic affiliation. New York: Routledge, 1998.

OROZCO GÓMEZ, G. Televisión y producción

de significados. Tres ensayos. Universidad de Guadalajara, Guadalajara, 1994.

PINHEIRO, A. Aquém da Identidade e da Oposição:

Formas na cultura mestiça. $2^{\mathrm{a}}$ ed. Piracicaba: Editora UNIMEP, 1995.

SANTIAGO, S. Glossário de Derrida. Rio: Francisco Alves, 1976.

SOUZA, L. M. T. M. Hibridismo e tradução cultural em Bhabha. In: ABDALA JÚNIOR, B. (Org.). Margens da cultura: mestiçagem, hibridismo \& outras misturas. São Paulo: Boitempo Editorial, 2004, p. 113-132.

TORRES, S. Crónicas de viaje chicanas: The Mixquiahuala Letters de Ana Castillo y Paletitas de guayaba de Erlinda González-Berry. In: DRISCOLL et al. Límites sociopoliticos y fronteras culturales en América del Norte. Cidade do México: UNAM/CISAN, 2000, p. 161-177. 


\section{Communicating differences: hybridization processes from the la différance conception in Cultural Studies}

\section{Abstract}

The article discusses the process of hybridization and the multiple readings of what being or becoming hybrid is. The approach starts with Jacques Derrida, with the discussion of the divided nature of the sign, "la différance", and continues by the consensual understandings (and some dissents) to theorists such as Stuart Hall, Homi Bhabha, Martín-Barbero and García Canclini locating, whenever possible, the reflections on the context of Latin America. We conclude that hybridization is potentially creative and at the same time troubled, not being limited to geographical, linguistic or any other border, but fluid, unsettling, ambiguous and almost often controversial.

\section{Keywords}

Hybridization. Cultural Studies.

Communication of differences. La différance.

\section{Comunicando diferencias:} los procesos de hibridación bajo la comprensión de la différance en los Estudios Culturales

\section{Resumen}

El artículo analiza el proceso de hibridación y múltiples lecturas de lo que el ser o llegar a ser híbrido. El enfoque comienza por Jacques Derrida, con la discusión sobre la naturaleza dividida de la señal, la différance, y continúa por entendimientos consensuales (y un poco de la disidencia) a teóricos como Stuart Hall, Homi Bhabha, Martín-Barbero y García Canclini - siempre que sea posible con reflexiones en el contexto de América Latina. Llegamos a la conclusión de que la hibridación es potencialmente creativo y al mismo tiempo preocupado, no se limita a las fronteras geográficas, lingüísticas o de otro tipo, y es fluida, inquietante, ambigua y, a menudo contradictorias.

\section{Palabras clave}

Hibridación. Estudios Culturales.

Comunicación de la diferencia. La différance. 


\section{Expediente}

A revista E-Compós é a publicação científica em formato eletrônico da Associação Nacional dos Programas de Pós-Graduação em Comunicação (Compós). Lançada em 2004, tem como principal finalidade difundir a produção acadêmica de pesquisadores da área de Comunicação, inseridos em instituições do Brasil e do exterior.

\section{E-COMPÓS I www.e-compos.org.br I E-ISSN 1808-2599}

Revista da Associação Nacional dos Programas de Pós-Graduação em Comunicação.

Brasília, v.18, n.1, jan./abri.. 2015.

A identificação das edições, a partir de 2008, passa a ser volume anual com três números.

\section{CONSELHO EDITORIAL}

Alexandre Rocha da Silva, Universidade Federal do Rio Grande do Sul, Brasil Alexandre Farbiarz, Universidade Federal Fluminense, Brasil Ana Carolina Damboriarena Escosteguy, Pontifícia Universidade Católica do Rio Grande do Sul, Brasil

Ana Carolina Rocha Pessôa Temer, Universidade Federal de Goiás, Brasil Ana Regina Barros Rego Leal, Universidade Federal do Piauí, Brasil André Luiz Martins Lemos, Universidade Federal da Bahia, Brasil Andrea França, Pontifícia Universidade Católica do Rio de Janeiro, Brasil Antonio Carlos Hohlfeldt, Pontifícia Universidade Católica do Rio Grande do Sul, Brasil

Arthur Ituassu, Pontifícia Universidade Católica do Rio de Janeiro, Brasil Álvaro Larangeira, Universidade Tuiuti do Paraná, Brasil Ângela Freire Prysthon, Universidade Federal de Pernambuco, Brasil César Geraldo Guimarães, Universidade Federal de Minas Gerais, Brasil Cláudio Novaes Pinto Coelho, Faculdade Cásper Líbero, Brasil Daisi Irmgard Vogel, Universidade Federal de Santa Catarina, Brasil Daniela Zanetti, Universidade Federal do Espírito Santo, Brasil Denize Correa Araujo, Universidade Tuiuti do Paraná, Brasil Eduardo Antonio de Jesus, Pontifícia Universidade Católica de Minas Gerais, Brasil

Eduardo Vicente, Universidade de São Paulo, Brasil

Elizabeth Moraes Gonçalves, Universidade Metodista de São Paulo, Brasil Erick Felinto de Oliveira, Universidade do Estado do Rio de Janeiro, Brasil Francisco Elinaldo Teixeira, Universidade Estadual de Campinas, Brasil Francisco Paulo Jamil Almeida Marques, Universidade Federal do Ceará, Brasil Gabriela Reinaldo, Universidade Federal do Ceará, Brasil Gisela Grangeiro da Silva Castro, Escola Superior de Propaganda e Marketing, Brasil

Goiamérico Felício Carneiro Santos, Universidade Federal de Goiás, Brasil Gustavo Daudt Fischer, Unisinos, Brasil

Herom Vargas, Universidade Municipal de São Caetano do Sul, Brasil
Itania Maria Mota Gomes, Universidade Federal da Bahia, Brasil Janice Caiafa, Universidade Federal do Rio de Janeiro, Brasil Jiani Adriana Bonin, Universidade do Vale do Rio dos Sinos, Brasil José Afonso da Silva Junior, Universidade Federal de Pernambuco, Brasil José Luiz Aidar Prado, Pontifícia Universidade Católica de São Paulo, Brasil Kati Caetano, Universidade Tuiuti do Paraná, Brasil

Lilian Cristina Monteiro França, Universidade Federal de Sergipe, Brasil Liziane Soares Guazina, Universidade de Brasília, Brasil Luíza Mônica Assis da Silva, Universidade de Caxias do Sul, Brasil Luciana Miranda Costa, Universidade Federal do Pará, Brasil Malena Segura Contrera, Universidade Paulista, Brasil Marcel Vieira Barreto Silva, Universidade Federal da Paraíba, Brasil Maria Ogécia Drigo, Universidade de Sorocaba, Brasil Maria Ataide Malcher, Universidade Federal do Pará, Brasil Maria Clotilde Perez Rodrigues, Universidade de São Paulo, Brasil Maria das Graças Pinto Coelho, Universidade Federal do Rio Grande do Norte, Brasil

Mauricio Ribeiro da Silva, Universidade Paulista, Brasil

Mauro de Souza Ventura, Universidade Estadual Paulista, Brasil Márcio Souza Gonçalves, Universidade do Estado do Rio de Janeiro, Brasil Micael Maiolino Herschmann, Universidade Federal do Rio de Janeiro, Brasil Mirna Feitoza Pereira, Universidade Federal do Amazonas, Brasil Nísia Martins Rosario, Universidade Federal do Rio Grande do Sul, Brasil Potiguara Mendes Silveira Jr, Universidade Federal de Juiz de Fora, Brasil Regiane Ribeiro, Universidade Federal do Paraná, Brasil Rogério Ferraraz, Universidade Anhembi Morumbi, Brasil Rose Melo Rocha, Escola Superior de Propaganda e Marketing, Brasil Rozinaldo Antonio Miani, Universidade Estadual de Londrina, Brasil Sérgio Luiz Gadini, Universidade Estadual de Ponta Grossa, Brasil Simone Maria Andrade Pereira de Sá, Universidade Federal Fluminense, Brasil Veneza Mayora Ronsini, Universidade Federal de Santa Maria, Brasil Walmir Albuquerque Barbosa, Universidade Federal do Amazonas, Brasil

\section{COMISSÃO EDITORIAL}

\section{Cristiane Freitas Gutfreind}

Pontifícia Universidade Católica do Rio Grande do Sul, Brasil

Irene Machado

Universidade de São Paulo, Brasil

Jorge Cardoso Filho

Universidade Federal do Reconcavo da Bahia, Brasil

Universidade Federal da Bahia, Brasil

\section{REVISÃO DE TEXTOS I Press Revisão SECRETÁRIA EXECUTIVA I Helena Stigger EDITORAÇÃO ELETRÔNICA I Roka Estúdio}

COMPÓS I www.compos.org.br

Associação Nacional dos Programas de Pós-Graduação em Comunicação

Presidente

Eduardo Morettin

Universidade de São Paulo, Brasil

eduardomorettin@usp.br

Vice-presidente

Inês Vitorino

Universidade Federal do Ceará, Brasil

ines@ufc.br

Secretária-Geral

Gislene da Silva

Universidade Federal de Santa Catarina, Brasil gislenedasilva@gmail.com 